\title{
Teaching Children with High Functioning Autism - What Teachers Understand About High Functioning Autism and What Support They Would Like to Receive
}

\author{
Debbie Williams
}

\begin{abstract}
Teachers are often faced with the challenge of teaching students with high functioning autism without any formal professional development in autism. Resource Teachers of Learning and Behaviour (RTLB) are a service which is able to provide short-term support for teachers. One of the roles of RTLB is to provide teachers with the required support to further develop their skills to enable them to effectively teach students with high functioning autism. The current study explored teachers' understanding of high functioning autism and aimed to identify what support teachers of these students would like to receive. Results indicated that, contrary to some previous studies, teachers have an understanding of the characteristics of autism. Results also identified support that teachers would like to receive. The supports identified are supports that RTLB are able to provide.
\end{abstract}

\section{Keywords:}

autism, teacher support

\section{Research paper}

\section{INTRODUCTION}

Autism Spectrum Disorder (ASD) umbrellas a number of disorders (Ministries of Health \& Education, 2008). The characteristics of autism spectrum disorder include impaired understanding and use of verbal and nonverbal communication, social behaviour, and the inability to think and behave flexibly. People with high functioning autism meet the criteria for autism but do not have an intellectual impairment and their language development may be average or even high (Ministries of Health and Education, 2008). New Zealand pre-service teacher education programmes often do not include content on teaching students with diverse needs (Chatfield \& Higginson, 2012). With the rate of students with autism attending inclusive schools increasing, teachers are almost certain to teach a student with autism within the first few years of their teaching career. Without training in ASD or support from professionals with knowledge of ASD, teachers are faced with a significant challenge when they have a student with autism in their inclusive classrooms (Callias, Helps \& Newsom-Davis, 1999).

One of the roles of RTLB is to work with teachers of students with learning or behaviour needs and to provide them with the support and guidance they need to further develop existing skills and to learn new skills as a teacher. RTLB are a service provided by the Ministry of Education. They offer short-term support for teachers of students with moderate needs. This service differs from the Special Education and Services (SE\&S). SE\&S is a service provided by the Ministry of Education for students with long-term high needs. Support for these students is provided through the Ongoing Resource Scheme (ORS) and often remains in place for the entire time a student attends school. RTLB receive many referrals to support teachers of students with high functioning autism. High functioning autism is not a visible difference. Unless a teacher knows that their student is on the autism spectrum or has knowledge of the characteristics of high functioning autism, their behaviours can easily be misinterpreted as non-compliance or poor behaviour choices. One of the challenges teachers face in developing their knowledge of the characteristics of high functioning autism is the fact that the characteristics can be quite different from one student with autism to another. No two students are the same (Able, Garwood, Schultz, Sherman \& Sreckovic, 2014). The number of students with autism attending mainstream schools is increasing (Able et al., 2014; Barned, Knapp \& Neuharth-Pritchett, 2011; Lindsay, Proulx, Scott \& Thomson, 2013). Teachers in mainstream schools in New Zealand will, on average, teach a student with autism at least once every four or five years (Chatfield \& Higginson, 2012). Despite the large number of students with autism attending mainstream schools, the process of meeting their learning and participation needs is complex and poorly understood (Barned, et al., 2011; Davis \& Florian, 2004 in Humphrey \& Lewis, 2008). Bryson, Corkum, Giffen, Hume, Power and Smith (2014) stated that teachers find it difficult to meet the wide-ranging and varying needs of students with autism in an inclusive environment, therefore 
training professionals to educate and support students with autism can be a significant challenge in the field of autism.

The issues and concerns raised by teachers in regards to the effective teaching of students with autism appear to be overwhelmingly universal (Burns, Leblanc $\&$ Richardson, 2009). The purpose of the current study was to explore what teachers know about high functioning autism and what support they would like to receive to assist them in meeting these students needs. There is little published New Zealand research in the area of teaching high functioning autistic students so the current study is timely and relevant. The data obtained from the current study is useful not only for RTLB but also for principals, special education needs co-ordinators and other education professionals such as those concerned with initial teacher education or those thinking about professional development and learning needs of teachers. It will further enable education professionals to meet the needs of teachers who request assistance and support for teaching students with high functioning autism.

\section{TEACHERS' UNDERSTANDING OF AUTISM}

Cassimos, Polychronopoulou, Syriopoulu-Delli and Tripsianis (2012) and Campbell and Segall (2012) stated that although some studies have acknowledged the importance of teachers' knowledge of ASD, there has not been a lot of research in this field. These authors distributed questionnaires to assess teachers' knowledge of autism. The studies clearly identified teachers' lack of knowledge of autism. Many teachers responded that they were not capable of recognising autistic characteristics and did not know that autism is hereditary (Cassimos et al., 2012). Over two thirds of teachers surveyed by Campbell and Segall (2012) thought that autism disorders only existed in childhood and that with proper interventions children would outgrow autism. Many teachers thought that autism could be caused by early childhood trauma. More than half thought that all children with autism are similar to one another. Over half did not know that the diagnosis for Asperger's Syndrome is the same as the diagnosis for high functioning autism (Campbelll \& Segall, 2012).

Research published by Mavropoulou and Padeliadu (2000), Barned et al. (2011) and Callias, Helps and Newsom-Davis (1999) found similarities with relation to the misconceptions revealed by Cassimos et al. (2012) and Campbell and Segall (2012) but their results also show evidence of teachers' correct knowledge of characteristics of autism. When Mavropoulou and Padeliadu surveyed pre-service teachers about the specifics of Asperger's Syndrome and high functioning autism, more than 80 percent had the correct understanding about the diagnostic criteria. This contradicts the findings of Campell and Segall. Teachers in the Barned et al. study understood that medication does not treat the core symptoms of autism and that the core characteristics of autism included social and language difficulties and sensory impairments (Barned et al., 2011). Teachers in the Callias et al. (1999) study were aware that classroom organisation such as predictability, explicit instruction and structure can make a difference to the behaviour of a student with autism.

\section{TEACHERS LACK PROFESSIONAL DEVELOPMENT}

Often teachers do not have enough professional development in the area of autism and this lack of professional development may contribute to the many challenges of working with students with autism in inclusive classrooms (Barnard, Broach, Potter \& Prior, 2002; Callias et al., (1999). Callias et al., in a study designed to gather information regarding professional development about autism received by teaching professionals and about their professional development needs, surveyed 72 teachers and support staff. The results revealed that although approximately 70 percent of the participants had worked with children on the autistic spectrum, only 5 percent had received specific professional development in their teaching qualification and 5 percent had attended in-service training days. Teachers in mainstream schools are working with students on the autistim spectrum without formal training or professional development in the area of autism ( Barnard et al., 2002; Callias et al., 1999).

\section{Teachers Want and Need to Receive Professional Development}

Lack of professional development has been identified as one of the challenges faced by teachers of children with autism in mainstream classrooms with some studies showing that teachers feel they lack adequate information about autism and how to work with students in their classroom (Lindsay, Proulx, Scott \& Thomson, 2013). However, studies inquiring about the willingness of teachers to receive professional development in the area of autism have been carried out in recent years (Clinton et al., 2014; Humphrey \& Symes, 2013). A major finding was that both beginning teachers and experienced teachers would like to receive professional development in teaching children with autism. Teachers have expressed the desire to not only participate but also implement professional development activities in the area of autism (Clinton et al., 2014). In a study by Humphrey and Symes (2013), as many as 80 percent of teachers - including members of senior management and special education needs coordinators - indicated a willingness to receive professional development on autism if it was made available. 
Even a small amount of professional development is helpful for teachers, especially beginning teachers, to work effectively with students with autism. A professional development session as small as three hours and twenty minutes is enough to increase knowledge of autism and evidence-based practices along with an increase in comfort levels with potentially teaching a student with autism (Burns et al., 2009). Teachers have reported that the most helpful professional development they have received was hands-on training, mentoring by colleagues with experience in teaching students with autism, and workshops held by the school and by outside agencies (Bryson et al., 2004).

\section{Additional Support Teachers Would Like to Receive}

Resource Teachers of Learning and Behaviour (RTLB) aim to support teachers to meet the needs of students with diverse needs in mainstream classrooms. In order to provide effective support for teachers working with students with high functioning autism we need to consider the support teachers have identified as useful to them. Studies have identified a comprehensive list of support that teachers would like to receive. For example, Glashan, MacKay and Grieve (2004) found that one of the most useful aspects of attending one day courses is the chance to meet other teachers in the same situation, and that one of the greatest needs of teachers is the reassurance that the strategies they have developed are acceptable. Teachers highlighted the need for collaboration between teachers, special education teachers, school psychologists and parents (Able et al., 2014). An important finding from Campbell and McGregor (2001) was that it is not only the teachers with little or no experience of teaching students with autism who would like to receive support but also the teachers with experience of teaching students with autism. Teachers experienced in teaching students with autism listed practical advice and strategies; observations and 'hands-on' experience with the student; regular contact and follow-ups with parents, teachers and students; advising teachers about individual needs in all areas of school life; training to raise awareness at school level; written guidelines and information on courses; programmes of study for the student, and exchange visits with other schools as supports they would find beneficial. Teachers without experience in teaching students with autism identified supports such as the demonstration of strategies, provision of material on autism and assistance with individual action plans as assistance they would consider helpful (Campbell \& McGregor, 2001).

As important as it is to consider support that teachers would like to receive, consideration also needs to be given to support that is offered but is viewed by teachers as ineffective or needing improvement.
Emam and Farrell (2009) have found that teachers want the support of a teacher-aide who works closely with the pupil and that the role of a teacher-aide is indispensable. However, Glashan, MacKay and Grieve (2004) found that although teacher-aides were regarded very highly, teachers were stressed by having to direct a teacher-aide when they didn't have the necessary knowledge themselves. Teachers felt that the support of a teacher-aide was adequate only if the teacher-aide had knowledge of autism. Teachers value collaboration between special education teachers and psychologists (Able et al., 2014) but teachers are sometimes confused about the role of special education teachers and how they can access the service (Glashan, MacKay \& Grieve, 2004).

The remainder of this paper discusses a small study investigating teachers' understanding of high functioning autism and what support they would like to receive to further develop their skills in teaching students with high functioning autism in mainstream classes.

\section{METHOD}

The study was carried out in one primary school in New Zealand. This particular school was chosen for two reasons. One, it is a large primary school with a high number of teaching staff and, two, because it is a school I have not worked in so there was no conflict of interest. Permission was gained from the school principal to conduct and publish this study. All teachers on the staff were invited to participate regardless of whether or not they had previously taught children with high functioning autism. The invitation to participate was also extended to the management team: they also teach in classrooms from time to time. Support staff were not invited to participate because the aim of the inquiry was to explore the knowledge and needs of teachers.

An introductory telephone call was made to the principal of the participating school and the topic and purpose of the inquiry was explained. This was followed by a letter and a copy of the questionnaire requesting permission to invite the teaching staff to participate. An information sheet explaining the purpose of the inquiry was personally distributed at a weekly staff meeting. Teachers were given the opportunity to ask questions and were encouraged to contact the researcher if they had any queries. Participants were given ten days to submit the completed questionnaire. A reminder was issued to the participants via the online daily staff notices after one week.

The data was gathered using a Survey Monkey questionnaire consisting of ten questions (see Appendix 1). 
The questionnaire was divided into four sections: teachers' knowledge of high functioning autism; professional development received by teachers; professional development teachers would like to receive, and support teachers would like to receive. The questions were designed to gather both quantitative and qualitative data. The questionnaire began by asking participants to indicate their experience of teaching students with high functioning autism. Three of the questions required a true or false response. Two questions were multi-choice where the participants were asked to choose all of the options that applied to them. These two questions included an 'other, please specify' option. Two questions asked the participants to rate a statement using a 5-point Likert scale and two questions required a brief written response. The questionnaires were automatically emailed to the researcher when participants submitted their completed questionnaire.

Thirty one teachers were invited to participate. Eleven teachers responded. Seven of the eleven teachers indicated that they had not had any experience of teaching children with high functioning autism.

Quantitative data was automatically analysed through Survey Monkey thus errors arising from faulty data management was avoided. Simple numerical techniques were used to analyse the data. Qualitative data collected as written responses were systematically recorded individually and have been included in the results.

\section{RESULTS}

\section{Teachers' Knowledge of High Functioning Autism}

Six questions in the questionnaire explored teachers' knowledge of high functioning autism. Results show that teachers in this study had a good understanding that interventions that work for one child with high functioning autism may not work for all. Teachers knew that not all children with high functioning autism have the same characteristics. More than half of the participants were aware that the diagnostic criteria for Asperger's Syndrome is the same as the criteria for high functioning autism. Nearly all of the teachers understood that autism is not caused by a traumatic experience early in life and that even with effective intervention children will not outgrow autism. All but one of the teachers who participated in this study were able to identify characteristics of high functioning autism. The majority listed anxiety, difficulties with social skills, social interactions and communication skills as what they considered to be the main characteristics of high functioning autism. Other characteristics listed were the dislike of change, repetitive noises and rhythm, hypersensitivity, being 'in their own world', and preoccupation with a special interest.

\section{Professional Development Received by Teachers}

Less than half of the participants indicated that they had received professional development in the area of high functioning autism during their teaching career. Two of the five participants who had received professional development completed courses specifically relating to ASD. The remaining three participants indicated that they had received professional development from their Special Education Needs Co-ordinator (SENCo), Resource Teacher of Learning and Behaviour (RTLB), Speech Language Therapist (SLT), Occupational Therapist (OT) and colleagues. Five participants did not respond to the question. It is assumed that these participants did not respond because they have not received professional development in this area.

\section{Table 1 Professional Development Teachers Would Like to Receive}

\begin{tabular}{|l|lc|}
\hline Types of professional development & Responses \\
\hline $\begin{array}{l}\text { Visiting other classrooms with students with } \\
\text { high functioning autism }\end{array}$ & 8 & $80 \%$ \\
\hline A series of workshops & 7 & $70 \%$ \\
\hline Training included in a staff meeting & 4 & $40 \%$ \\
\hline One day workshop & 3 & $30 \%$ \\
\hline Other suggestions & 2 & $20 \%$ \\
\hline
\end{tabular}

*Note: only 10 of the 11 teachers responded to this question

Participants were asked to choose the types of professional development they would find helpful from a list of four examples of professional development. The responses indicated that most teachers would like the opportunity to visit other classrooms with students with high functioning autism. Other suggestions of professional development participants would like to receive were short overviews and a series of workshops where the teachers try out strategies in between workshops. One participant did not respond to this question.

\section{Table 2 Support Teachers Would Like to Receive}

\begin{tabular}{|c|c|}
\hline Types of support for teachers & Responses \\
\hline $\begin{array}{l}\text { Working alongside professionals trained to } \\
\text { work with students with high functioning } \\
\text { autism }\end{array}$ & $11 \quad 100 \%$ \\
\hline Practical advice and strategies & $11 \quad 100 \%$ \\
\hline $\begin{array}{l}\text { Support from colleagues with more experience } \\
\text { with teaching children with high functioning } \\
\text { autism. }\end{array}$ & $1091 \%$ \\
\hline Resources & $10 \quad 91 \%$ \\
\hline Teacher-aide & $10 \quad 91 \%$ \\
\hline Encouragement and reassurance & $73 \%$ \\
\hline Other suggestions & $9 \%$ \\
\hline Total respondents 11 & \\
\hline
\end{tabular}


Participants were asked to identify what types of supports they would like to receive if they had a child in their class with high functioning autism. They were provided with a list of suggested types of support and were asked to choose all supports they would find helpful and also specify any other support they would find helpful. In addition to the suggested types of support provided in the questionnaire, one participant specified time to work one-to-one with the student to gain an understanding of how the individual thinks and works, support tailored to the individual needs of the student, and support with communication skills as other support that would be helpful to teachers.

\section{DISCUSSION}

The aim of this study was to investigate two questions: 1) What are teachers' understandings about teaching students with high functioning autism? and 2) What support would teachers like to receive to increase their confidence in teaching students with high functioning autism in their mainstream class? The purpose of exploring these two questions was to provide RTLB with data to further enable effective support and assistance for teachers of students with high functioning autism

Results indicate that the teachers in this study have an understanding of high functioning autism as evidenced in the high percentage of correct responses to the survey questions relating to teachers' knowledge. The majority of the participants understood the similarities between the diagnostic criteria for high functioning autism and Asperger's Syndrome and that autism is not caused through a traumatic experience. Most participants knew that children will not outgrow autism even with an effective intervention and that one intervention will not necessarily be effective for all children with high functioning autism. Participants were able to list a variety of characteristics of high functioning autism. These results differ to the findings of Cassimos et al. (2012) and Campbell and Segall (2012) who identified teachers lacked knowledge in all of the knowledge-based questions asked in the current study. A possible reason for this contradiction in findings may be that teachers are becoming more aware of autism due to the increase in the number of children diagnosed with autism in recent years (Able et al., 2014; Barned et al., 2011; Lindsay et al., 2013).

Despite the increase in students with autism in schools (Barnard et al., 2002; Callias et al., 1999) teachers in this study indicated a lack of professional development in the area of autism. Five participants did not answer the question asking if they had received professional development in the area of high functioning autism. The assumption could be made from this lack of response that these teachers had not received professional development. These results are consistent with the findings of Callias et al. (1999) and Barnard et al. (2002).

Other important findings of this study are that teachers would like to receive some form of professional development in high functioning autism. Of the four professional development options listed in the questionnaire for participants to choose from, most teachers indicated that they would like to visit other classrooms with students with high functioning autism. This form of professional development is aligned with the new approach to professional learning and development recently announced by the Minister of Education (Parata, 2015). An advisory group was established to provide a report to the Ministry of Education which sets out their thinking about a new approach and principles for professional learning and development (Professional Learning and Development Advisory Group, 2014). Evidence in the report suggests that professional learning development is effective when leaders and teachers collaborate with colleagues internal or external to the school. Barrar, Fung, Timperley and Wilson (2007) report that teachers getting together in formal learning opportunities or less-formal discussion groups and talking about problems is a valuable form of learning. The idea of professionals learning from and with each other is not new. Rogoff (1994) wrote that the concept of a community of learners is based on the premise that people learn as they participate in shared undertakings with others with all playing active roles. This contrasts with models of learning based on the belief that learning occurs through transmission of knowledge from experts to the learner who plays a passive role.

Teachers in this study have clearly indicated that they want to receive professional development in the area of high functioning autism. It was clearly indicated that they would value support in the form of working alongside professionals trained to work with students with high functioning autism and receiving support from colleagues with more experience with teaching children with high functioning autism. This finding is evidence that teachers want to engage in learning opportunities such as the community of learners described by Rogoff (1994). Interestingly, only a few teachers indicated that they would be keen to attend a one day workshop. Although one day presentations and workshops have been described as 'one hit wonders' (Chatfield \& Higginson, 2012), Burns et al. (2009) reported that small amounts of professional development are helpful for teachers working with students with autism. This finding could be an indication that professional development considered beneficial to teachers is moving away from 
the learning model where experts deliver the content to communities of practice where learners learn from each other.

Professional development is one way of supporting teachers to effectively teach students with high functioning autism but there are other forms of support available for teachers. One of the aims of the current study was to inquire about additional support teachers might like to receive. Participants were asked to choose from a list of five possible supports for teachers of high functioning autistic students in mainstream classes that they would like to receive. Nearly all of the participants indicated they would like teacheraide support and the majority indicated that all five choices would be forms of support they would like. There is no way to know if the participants chose the supports because they are supports they would find helpful or if they chose them simply because they were the supports listed in the questionnaire. If the supports were chosen because they are examples of support that teachers would value, this identifies implications for RTLB. Teacher-aide support, practical advice and strategies, support from colleagues with more experience with teaching children with high functioning autism, resources, encouragement and reassurance, and working alongside professionals to work with students with high functioning autism are all supports that RTLB are able to provide.

The findings from the current study highlight the need for RTLB to ensure that teachers are aware of the support they are able to provide and how they can access this support to enable them to further develop their skills in teaching students with high functioning autism.

\section{LIMITATIONS}

While the results of the current study provides some valuable suggestions for RTLB there are limitations in the research which need to be considered for future studies. One important limitation of the current study is the small sample size. The participating school was chosen because of the large number of teaching staff but despite meeting with the staff to explain the purpose of the study only 35 percent participated in the survey. A further limitation was the limited number of response choices associated with some questions. More responses in the text boxes would have provided further data. A further limitation was the length of the questionnaire, it contained only ten questions. More data could have been obtained if the questionnaire contained more questions, however this had to be weighted up with the need for the questionnaire to be able to be completed in a very short time as teachers are very busy people and they do not have time to participate in lengthy surveys.

\section{CONCLUSIONS}

Research clearly shows that teachers would like to receive professional development in the area of teaching students with autism and they are willing to engage in professional development courses to increase their knowledge and confidence to effectively teach students with autism in mainstream classes. It is not only teachers with little or no experience of teaching students with autism who are seeking knowledge and support but also teachers who have had experience with students with autism.

Teachers have identified working alongside professionals trained to work with students with high functioning autism and practical advice and strategies as forms of support they would like to receive to assist them with teaching students with autism. Teachers identified visiting other classrooms with students with high functioning autism as professional development they would find helpful. These findings support the new approach to professional learning and development reported to the Ministry of Education by the Professional Learning and Development Advisory Group (2014).

Findings from this study highlights implications for RTLB. The support and professional development that teachers are asking for can be provided by RTLB. The Resource Teacher of Learning and Behaviour Service Toolkit states that schools can expect that RTLB will work alongside teachers to provide practical support and advice, assist to build teacher capability and collaborate with other agencies. Through a seamless approach, RTLB will enable teachers to meet the needs of diverse learners (Ministry of Education, n.d).

\section{REFERENCES}

Able, H., Garwood, J., Schultz, T., Sherman, J., \& Sreckovic, M. (2014). Views from the trenches: Teacher and student supports needed for full inclusion of students with ASD. Teacher Education and Special Education: The Journal of the Teacher Education Division of the Council for Exceptional Children, 38(1), 44-57. doi: 10.1177/0888406414558096

Barnard, J., Broach, S., Potter, D., \& Prior, A. (2002). Autism in Scotland's schools crisis or challenge? London: The National Autistic Society.

Barned, N., Kanpp, N., \& Neuharth-Pritchett, S. (2011). Knowledge and attitudes of early childhood preservice teachers regarding the inclusion of children with autism spectrum disorder. Journal of Early Childhood Teacher Education, 32(4), 302-321. doi: 10.1080/10901027.2011.622235 
Barrar, H., Fung, I., Timperley, H., \& Wilson, A. (2007). Teacher professional learning and development: Best evidence synthesis. Wellington, New Zealand: Ministry of Education.

Bryson, S., Corkum, P., Giffen, C., Hume, K., Power, A., \& Smith, I. (2014). Professional development needs for educators working with autistic spectrum disorders in inclusive school environment. Exceptionality Education International, 24(1), 33-47.

Burns, K., Leblanc, L., \& Richardson, W. (2009). Autism spectrum disorder and the inclusive classroom. Effective training to enhance knowledge of ASD and evidence-based practices. Teacher Education and Special Education, 32(3), 166-179. doi: 10.177/0741932507334279

Campbell, E., \& McGregor, E. (2001). The attitudes of teachers in Scotland to the integration of children with autism into mainstream schools. Autism, 5(2), 189-207.

Campbell, J., \& Segall, M. (2012). Factors relating to education professsionals' classroom practices for the inclusion of students with autism spectrum disorders. Research in Autism Spectrum Disorders, 6(3), 1156-1167. doi: 10.1016/j.rasd.2012.02.007

Cassimos, D., Polychronopoulou, S., Syriopoulu-Delli, C., \& Tripsianis, G. (2012). Teachers' perceptions regarding the management of children with autism spectrum disorders. J Autism Dev Discord, 42(5), 755-768. doi: 10.1007/s10803-011-1309-7

Callias, M., Helps, S., \& Newsom-Davis, I. (1999). Autism. The teacher's view. Autism, 3(3), 287-298.

Chatfield, M., \& Higginson, R. (2012). Together we can do it: A professional development project for regular teachers of children with autism spectrum disorder. Kairaranga, 13(2), 29-40.

Clinton, C., Conn, K., Dean, M., Harwood, R., Heinert, S., Hetherington, S., Huynh, L., Kasari, C., Kataoka, S., Ladrola, S., Locke, J., Mandell, D., Reisinger, S., \& Smith, T. (2014). Services for children with autism spectrum disorder in three, large urban school districts: Perspectives of parents and educators. Autism. doi: 10.1177/13622361314548078

Emam, M., \& Farrell, P. (2009). Tensions experienced by teachers and their views of support for pupils with autism spectrum disorders in mainstream schools. European Journal of Special Needs Education, 24(4), 407-422. doi: 10.1080/08856250903223070

Glashan, L., MacKay, G., \& Grieve, A. (2004). Teachers' experience of support in the mainstream education of pupils with autism. Improving Schools, 7(1), 49-60. doi: 10.1177/1365480204042113
Humphrey, N., \& Lewis, S. (2008). Make me normal. The views and experiences of pupils on the autistic spectrum in mainstream secondary schools. Autism, 12(1), 23-46. doi: 10.1177/1362361307085267

Humphrey, N., \& Symes, W. (2013). Inclusive education for pupils with autistic spectrum disorders in secondary mainstream schools: Teacher attitudes, experience and knowledge. International Journal of Inclusive Education, 17(1), 32-46. doi: 10.1080/13603116.2011.580462

Lindsay, S., Proulx, M., Scott, H., \& Thomson, N. (2013). Educators' challenges of including children with autism spectrum disorder in mainstream classrooms. International Journal of Disability, Development and Education, 60(4), 347-362. doi: 10.1080/1034912x.2013.846470

Mavropoulou, S., \& Padeliadu, S. (2000). Greek teachers' perceptions of autism and implications for educational practice. Autism, 4(2), 173-183.

Ministry of Education (n.d). Resource Teacher: Learning and Behaviour Service Toolkit: RTLB Management. Wellington, New Zealand: Author. Retrieved from http://rtlb.tki.org.nz/

Ministries of Health and Education (2008). New Zealand Autism Spectrum Disorder Guideline. Wellington, New Zealand: Ministry of Health.

Parata, H. (2015). PLD changes will lift student achievement. Retrieved from https://www.beehive.govt.nz/release/pld-changeswill-lift-student-achievement

Professional Learning and Development Advisory Group (2014). Report of the professional learning and development advisory group. Retrieved from: http://www.education.govt.nz/assets/Documents/ Ministry/Initiatives/PLDAdvisoryGroupReport.pdf

Rogoff, B. (1994). Developing understanding of the idea of communities of learners. Mind, Culture, and Activity, 209-229 1(4). 
APPENDIX ONE: Questionnaire on teaching children with high functioning autism

1. Have you taught children with high functioning autism?
$\square$ No
$\square$ Yes. Between 1 and 5 students.

$\square$ Yes. More than 5 students.

2. The diagnostic criteria for Asperger's Syndrome is the same as the criteria for high functioning autism.
$\square$ True
$\square$ False

3. Traumatic experience early in life can cause autism.
$\square$ True
$\square$ False

4. With effective intervention most children with high functioning autism will outgrow the disorder.
$\square$ True
$\square$ False

5. Children with high functioning autism all have the same characteristics.
$\square$ Strongly agree
$\square$ Agree
$\square$ Not sure
$\square$ Disagree
$\square$ Strongly disagree

6. If an intervention works for one child with high functioning autism it will work for all children with high functioning autism.
$\square$ Strongly agree
$\square$ Agree
$\square$ Not sure
$\square$ Disagree
$\square$ Strongly disagree

7. If you are aware of any characteristics of high functioning autism, what are the three main characteristics that you know of?

8. What support do you think you would like to receive if you had a child in your class with high functioning autism? (choose all that you would find helpful)

$\square$ Teacher-aide

$\square$ Practical advice and strategies
Support from colleagues with more experience with teaching children with high functioning autism

$\square$ Resources

$\square$ Encouragement and reassurance

$\square$ Working alongside professionals trained to work with students with high functioning autism

$\square$ Other (please specify)

9. If you have received any professional development in the area of high functioning autism, what was the professional development and how useful was it to you?

10. If you think you would benefit from in-service training in the area of high functioning autism, what sort of training would you like to receive? (choose all that you would find helpful)

$\square$ One day workshop

$\square$ Training included in a staff meeting

$\square$ A series of workshops

$\square$ Visiting other schools with students with high functioning autism

$\square$ Other (please specify)

\section{AUTHOR PROFILE}

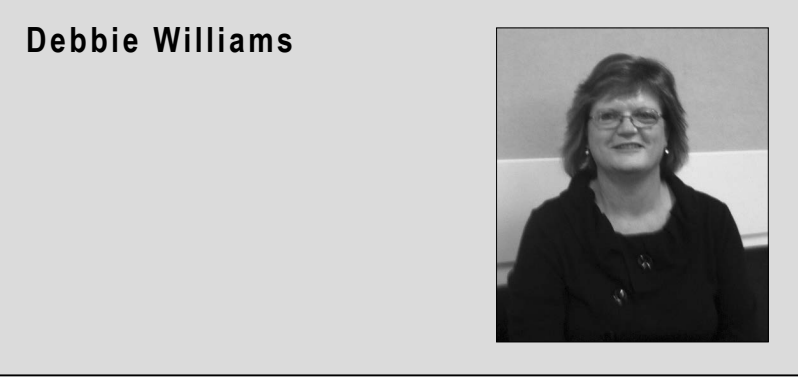

Debbie Williams is a Resource Teacher of Learning and Behaviour working in the Horowhenua region. Her teaching career began as a teacher-aide before completing her diploma of teaching at Massey University College of Education. Debbie completed her Bachelor of Education as an extramural student and she has recently completed her Master in Specialist Teaching.

Email: dwilliams@tewhirikoko.ac.nz 